\title{
Programa Puente en Chile: ¿un avance hacia la construcción de sujetos? ${ }^{1}$
}

\author{
Paula Francisca Vidal Molina*
}

\begin{abstract}
Resumen
Lo que a continuación se presenta son los hallazgos de la Investigación denominada "Representación Social de la Pobreza desde el Programa Puente" la cual da cuenta de algunos de los nudos y contradicciones que se han visibilizado durante la ejecución de dicho Programa, como apuesta nacional que intenta superar la Extrema Pobreza o se pretende como parte de un sistema de protección social. Este estudio indaga en los sujetos que diseñan e implementan la política social con relación al discurso o visión que poseen de la pobreza, la práctica que realizan y los espacios de coherencia existentes entre ellos, ámbito que no es considerado a la hora de evaluar impacto o procesos que ha instalado la ejecución de este programa.
\end{abstract}

\section{Palabras clave}

Pobreza, representaciones sociales, extrema pobreza, programas sociales

\section{Abstract}

This article presents the results of the denominated research "Social Representation of the Poverty in the Program Bridge" that indicate some barriers and contradictions visualized during the execution of this Program, like national objective, that tries to surpass the Extreme Poverty or like part of a system of social protection. This study, investigates in the subjects that design and implement the social politics in relation to the speech or vision that they have of the poverty, the practice which they make and the existing spaces of coherence among them, scope who are not considered at the to evaluate their impact or processes that the execution of this one program has installed.

\section{Keywords}

Social representations, poverty, social programs.
1 Este texto es parte de los hallazgos de la tesis presentada para obtener el grado académico de Magíster en Antropología y Desarrollo.

* Licenciada en Trabajo Social Pontificia Universidad Católica de Chile, Magíster en Antropología y Desarrollo Universidad de Chile.

\section{Presentación}

T as diversas maneras de concebir y abordar la pobreza desde la política pública a lo largo de la historia en Chile da cuenta de los resultados que hoy se mantienen a nivel de índices de pobreza, pero también a nivel de las desigualdades que siguen acrecentándose en el país. El Programa Puente se ubica al interior de la contradicción instalada en nuestra sociedad, es decir, en un modelo de desarrollo que pretende mejorar los índices de crecimiento y desarrollo social, pero que, a la vez, convive con procesos de regresión social y desigualdad. Se plantea como un tipo de intervención que no supera la pobreza, pero sí lo hace con la extrema pobreza en tanto es capaz de poner en juego las fortalezas y capacidades de las familias, como también las redes institucionales a través de un agente estatal que interviene directamente con las personas/familias. Sin embargo, no se conoce acerca de los efectos paradojales que puede generar la 
intervención del Agente Estatal o Apoyo Familiar con las familias o alguno de sus miembros. Este último punto es de vital importancia dado que este Programa se ha considerado innovador en el quehacer del Trabajo Social realizado en el ámbito municipal chileno y las políticas sociales.

\section{Algo de Historia de las Políticas Sociales Chilenas}

Es deseable partir haciendo la siguiente afirmación: la noción de Pobreza y de Política Social es una construcción. Ambas nociones han variado a lo largo de la historia. Sin embargo, hoy la pobreza parece ser algo objetivo, externo a lo que podamos pensar de ella, con sujetos de carne y hueso que la padecen, los cuales requerirían apoyo de parte de la sociedad, a través de las políticas que el Estado puede elaborar. Así, la política social ${ }^{2}$ que el Estado chileno ha desarrollado en diversos períodos históricos ha sido consecuente con el modelo de desarrollo imperante en una época y al marco conceptual e ideológico en que los gobiernos se desenvuelven.

El origen de la política social en nuestro país se remonta a los años veinte, gracias a los inicios de la industria y de la urbanización, tendió a crecer la clase obrera del sector productivo lo cual trajo aparejado problemas laborales y precaria calidad de vida de estos obreros. Después de largas discusiones, se legisla, a partir de 1924, en torno a vivienda, salud y relaciones laborales. Las ideas de ese entonces que plasmaron el ambiente gubernamental eran de orden humanista, reformista y libertario, en donde el Estado, a través de la política social, debía proteger al trabajador y promover cambios sociales

2 "La política social es un fenómeno específicamente moderno: se trata de una acción racional del Estado tendiente a compensar a los sectores sociales desfavorecidos por el mercado, asegurándoles la satisfacción de ciertas necesidades elementales (...) se ha referido y ha actuado principalmente en los ámbitos laboral, de vivienda, salud, educación y seguridad social" (Martínez y Palacios, 1996: 175). graduales que dieran a la población condiciones de vida más igualitarias y justas. ${ }^{3}$

En el segundo período, la política social se caracteriza por estar ligada a una noción de Estado Benefactor y no protector, por medio del cual se promovió un gran desarrollo social e industrial del país. Se dictan leyes sociales, se extiende la enseñanza primaria, secundaria y superior, se electrifica el país, entre otras cosas. "Los gastos sociales se triplicaron en el período cubierto, entre 1930 y 1955; sobresalen los gastos en previsión social, seguidos por salud y vivienda, los que se reflejan tanto en una expansión de los servicios como en el mejoramiento en la calidad de éstos.” (Martínez y Palacios, 1996:180).

Para José Arellano, según Martínez y Palacios, la posibilidad de acceso a los servicios y beneficios sociales estaba fuertemente posibilitada y condicionada por las diferencias sociales y el peso político de cada sector laboral y social. Así es cómo el acceso de la clase media al poder político tuvo dos significados desde el punto de vista de la política social, en los gobiernos radicales: $1^{\circ}$ de ascenso (desde los años veinte a la segunda guerra mundial), en donde las políticas sociales se caracterizan por un efecto democratizador para el conjunto de las clases asalariadas. $2^{\circ}$ de asentamiento, en donde se privilegió a la clase media, deformando el efecto democratizador anterior.

Hacia 1960, el sistema mostraba crecientes dificultades para responder a las necesidades y las demandas de la población. El gasto público al crecer y no tener una contraparte en los ingresos ocasionó desequilibrios presupuestarios que intensificaron las presiones inflacionarias existentes en la economía (Raczynski, 1995:220). Dada esta situación y con

3 "Las reformas de Alessandri respondían fundamentalmente a las ideas del Partido Radical y del sector progresista del Partido Liberal, las que se plasmaron en un conjunto de medidas tendientes a la "protección del proletariado", expresadas fundamentalmente en el Código del Trabajo (1931). El Estado se constituyó como protector de los trabajadores asalariados" (Martínez y Palacios, 1996:177). 
la llegada al gobierno de la Democracia Cristiana, el gasto social se reduce y se impulsa una política social que pretende incorporar a los grupos marginales de la sociedad a la "integración nacional real” desde la promoción popular.

Por otro lado, las políticas sociales aplicadas en la Unidad Popular se diferenciaron de la tendencia aplicada durante años anteriores, en el sentido de que intentaron "ir más allá de la distribución de los bienes y servicios de la sociedad, para llegar a la distribución del poder, tanto económico como político, traspasándolo desde la clase dirigente hacia las mayorías desposeídas” (Martínez y Palacios, 1996:186). Este gobierno fue el último en que se dictó desde el Estado la totalidad de las políticas sociales, y en que éste era responsable fundamental del bienestar de la población.

Desde 1973 en adelante, con la instauración del gobierno militar, al Estado se le atribuye una gran ineficiencia en la tarea distributiva, el crecimiento económico será considerado como la vía privilegiada para mejorar el bienestar económico de la población; la política social se focaliza entonces en la erradicación de la extrema pobreza. El Estado asume un rol subsidiario, con una reducida capacidad de intervención. Es decir, sólo podía hacerlo en aquellas esferas en las cuales los particulares y las organizaciones de carácter intermedio no fueran capaces de desempeñarse por sí solos.

El modelo de desarrollo neoliberal, del gobierno militar, traía aparejado cuidar dos conceptos: la libertad individual ${ }^{4} \mathrm{y}$ la igualdad de oportunidades ${ }^{5}$,

4 "La libertad individual era entendida principalmente como la facultad de poder escoger en el mercado los bienes y servicios que se desearan, incluyendo la provisión de bienes y servicios que se desearan, incluyendo la provisión de bienes y servicios sociales básicos, y las relaciones de trabajo" (Mideplan, 1991:9).

5 "La igualdad de oportunidades se definió como la ausencia de discriminación que sólo podría obtenerse en el mercado, es decir, el resguardo del poder arbitrario y discrecional de las burocracias públicas. La consecución de igualdad requería, además, asegurar a toda la población la posibilidad de satisfacer sus necesidades mínimas de alimentación, salud y educación" (Mideplan, 1991: 91 los cuales desembocaron en: la focalización del gasto social en el estrato pobre y la entrada de la empresa privada y del mercado en áreas que históricamente le fueron ajenas como son salud, educación, previsión y vivienda. Tendiendo, entonces, a descentralizar el poder de decisión y transformar el mecanismo de financiamiento en dichas áreas.

Durante el régimen militar, las políticas sociales respondieron a un criterio económico, es decir, reducir el gasto social al máximo posible, disminuyendo los beneficios e incorporando el mercado como ente proveedor de ciertos servicios.

Con la llegada de la Concertación por la Democracia al gobierno, se mantuvieron los rasgos esenciales del modelo de desarrollo económico del anterior período, pero se acentuó la necesidad de introducir cambios en materias sociales que tendieran a mayores grados de justicia distributiva y equidad, "se postuló mantener una economía abierta y competitiva, en que el Estado intenta complementar el esfuerzo que hace el sector privado para promover el crecimiento, invirtiendo en aquellos ámbitos donde la rentabilidad social es mayor que la privada. Esta complementariedad entre el mercado y la acción pública se consideraba positiva en tanto convergieran la participación social y la concertación de intereses entre los distintos grupos sociales y políticos” (Martínez y Palacios, 1996:193).

La política social, en este período, se definió en función de cinco principios orientadores: solidaridad y equidad $^{6}$, integralidad ${ }^{7}$, participación, eficiencia e inversión social ${ }^{8}$.

6 Prioriza por aquellos que tienen menores recursos y permite igualar oportunidades.

7 Debe actuar en distintas dimensiones : económica, cultural, social, ambiental, para permitir mejorar la calidad de vida de la población. Asimismo, se traduce en acciones en las siguientes áreas: mejoramiento de la atención de salud, mejoramiento de la calidad de la educación y la capacitación ocupacional para los jóvenes que han desertado de la enseñanza media y el apoyo y promoción de los pequeños empresarios.

8 Se apoya no sólo a los hogares más pobres, sino también a grupos etáreos y productivos pobres que son potencialmente capaces de desarrollarse y llevar con ellos a los demás. 


\section{Algunos rasgos de la noción de Pobreza en los gobiernos militar y de la concertación}

Para el neoliberalismo, el crecimiento económico constituye la política para la superación de la pobreza, o de otra manera, el crecimiento económico es la principal política social. En ese sentido, “a medida que se superan las barreras básicas de pobreza, o sea, en la medida en que la gente sobrevive, se nutre adecuadamente y se educa, las personas pobres terminan subiendo cada vez más su nivel de aspiraciones. Por lo tanto, las necesidades siguen existiendo y las demandas se van haciendo cada vez más exigentes y mejor formuladas.” (Matte, 1994:93).

La pobreza, durante el gobierno militar, se definió en función de un criterio absoluto o estructural ${ }^{9}$, en donde el Estado debía hacerse responsable de cuidar a la madre embarazada y al niño recién nacido producto de los altos niveles de mortalidad infantil, bajar los niveles de desnutrición, bajar los niveles de deserción escolar, de repitencia, entre otros, desde una mirada principalmente asistencial o paternalista, en donde el sujeto sólo es receptor o depósito, de lo que otros creen que es lo necesario para dejar de ser pobre.

La focalización pasó a ser la forma de disminuir el gasto social, pero también cumplió la función de paliar los efectos negativos dejados por la aplicación de la política económica privilegiando a los sectores de extrema pobreza. Para Pilar Vergara, la acción del Estado, durante el régimen militar, fue dual en el ámbito social. Por un lado, para un sector de la población, privatización y libre elección en el mercado, por otro, asistencialismo y dependencia de subsidios estatales destinados

9 Pobreza absoluta se entendía como "la incapacidad de un individuo o su núcleo familiar de alcanzar ciertos niveles mínimos de satisfacción de un conjunto de necesidades consideradas imprescindibles" (Odeplan, 1983 en Vergara, 1990:36) a asegurar la subsistencia y dudosamente la movilidad social.

Los gobiernos de la concertación coinciden en que el crecimiento económico es el mecanismo fundamental para solucionar la pobreza, "para superarla (la pobreza) hay que crear riquezas y para eso es indispensable mantener ciertas características que ya tiene la economía chilena: su macroeconomía, su creciente esfuerzo de ahorro e inversión, su dinamismo exportador” (García, 1994:109). Sin embargo, a ello le agregaron la necesidad de aumentar el gasto social, mejorar la focalización de la política social, en el sentido de incorporar los nuevos problemas que presentan los pobres, en cuanto a territorialidad y/o grupos vulnerables ${ }^{10}$.

Asimismo, transitar desde la política asistencial hacia políticas que habilitan para participar en el desarrollo, esto se traduce "En 1989 los subsidios asistenciales representaban el $11 \%$ del gasto social; hoy día, el 6\%. Todos los recursos que dejaron de utilizarse se destinaron a programas de apoyo a la pequeña empresa, a facilitar su acceso al crédito y a ciertos subsidios que daba el Estado, pero a los que no podían acceder las pequeñas empresas (...) Lo que se dejó de usar en gasto asistencial pasó a utilizarse en gastos que habilitan a los pequeños productores que contratan al 40\% de los chilenos y al $80 \%$ de los pobres.” (García, 1994:111).

Así, la política social del primer gobierno de la Concertación priorizó por la inversión social o inversión en la gente, buscando actuar en diversas dimensiones de la pobreza: económica, social, cultural y ambiental, no sólo desde la perspectiva asistencial, sino también incorporando un compo-

10 Los grupo vulnerables definidos como prioritarios a comienzos de los Gobiernos de la Concertación fueron los niños y jóvenes, las mujeres de escasos recursos, los adultos mayores, discapacitados y pequeños productores. 
nente potenciador de las iniciativas de autoayuda y productivas de los pobres ${ }^{11}$.

11 Ejemplo de esto son el Programa Chile Barrio y el Programa Entre Todos. El primero tiene su origen en 1996 en donde el Comité Social de Ministros, concluye que existe una baja cobertura de los programas de vivienda para la población que se ubicaba en los dos primeros quintiles de distribución del ingreso. Por otra parte, Mideplan y Fosis habían encargado un estudio catastral de los asentamientos precarios del país, el cual permitiría dimensionar y localizar territorialmente el problema, y además, mostraría su correlación con variables de pobreza dura y marginalidad, a partir de lo cual, se pudiera diseñar un programa focalizado que aportara a la superación de la pobreza. A partir de lo anterior, se elabora una caracterización de la pobreza, determinando que "las personas que viven en estos asentamientos precarios presentan importantes carencias materiales ( viviendas inadecuadas, ausencia de servicios básicos como alcantarillado, agua potable, luz eléctrica y accesos irregulares), como a su vez, estrategias de sobrevivencia precarias y débiles, las que reflejan la informalidad e inestabilidad de los puestos de trabajo; y marginalidad respecto de las oportunidades que ofrece el país. En síntesis, exclusión de los mecanismos institucionales, tanto del mercado como de las políticas públicas para acceder a condiciones de vida y trabajo adecuados" (Muñoz, 1999). Así, el programa se plantea como misión "Contribuir a través de una acción integrada a la superación de la pobreza de los habitantes de asentamientos precarios del país, mediante el mejoramientos sustancial de su situación residencial, de la calidad de sus hábitat y de sus oportunidades de inserción social y laboral" (Programa Chile Barrio, 1998). Para el logro de esto, se ha planteado como estrategia el Complementar y Coordinar recursos financieros y capacidades técnicas de ministerios y servicios públicos con los del mundo privado, representado, éste último, por las organizaciones de la sociedad civil y del ámbito empresarial, de modo de ponerlos a disposición de la población que habita en asentamientos, para concebir proyectos articulados de superación de pobreza en el ámbito local. Los ámbitos de acción definidos son: desarrollo comunitario e inserción social, habilitación laboral y productiva, mejoramiento de la vivienda y del barrio y apoyo al fortalecimiento institucional en torno a programas de superación de pobreza. El Programa "Entre Todos" impulsado por el Fosis, se propuso generar capacidades para que sectores pobres identificaran colectivamente sus necesidades prioritarias y las satisfacieran, asumiendo un papel protagónico en la formulación, elaboración y ejecución de proyectos. La visión de la pobreza que posee es de tipo geográfica o territorial, es decir, el vivir la pobreza "limita la posibilidad de acceder a recursos y oportunidades que permitan superarla. Esta limitación es más intensa cuando la pobreza se vive en un entorno pobre" (Raczynski, 1995:250). Los objetivos del Programa eran: estimular la capacidad de organización y de iniciativa en las localidades pobres, reforzar las capacidades promocionales existente en las regiones y coordinar los esfuerzos $y$ recursos institucionales existentes $y$ canalizarlos preferentemente a las localidades pobres y extraer de las experiencias concretas de promoción a nivel de las
A partir del tercer gobierno de la concertación, lo que se advierte es que existe un tipo de pobreza resistente, frente a la cual los programas gubernamentales no logran los resultados propuestos, no tanto por sus contenidos, sino que no llegan a las personas más pobres. Frente a esto, se evalúa que la estrategia de las políticas públicas no ha sido la adecuada. Así, un primer elemento para redefinir la lucha contra la pobreza es revisar la focalización. Por otra parte, se asume más decididamente la idea, que viene hace tiempo desarrollándose, sobre la multiplicidad de dimensiones que componen la condición de pobre, y la necesidad de actuar frente a todas ellas. La acción no se limita, entonces, a proveer de empleo y de ingresos, sino de subsanar las carencias que estas personas tienen en otros ámbitos, como es el capital humano y el capital cultural. Un factor que juega también como déficit es la dispersión institucional y programática de la acción pública. Por ello, el problema de la pobreza es múltiple, involucra muchas acciones y requiere un enfoque integral. A partir de lo anterior, el Estado, a través de la política social asume un rol proactivo, el cual se traduce en que identifica su población objetivo (las familias en extrema pobreza) y acude a entregarles las prestaciones a través de un trabajo directo y personalizado. Aspecto que rompe con la tradicional dinámica de la política social de responder a la demanda que hacen los propios individuos o colectivos.

La implementación del Programa Puente es un ejemplo de lo anterior, en donde la pobreza es concebida desde las potencialidades que poseen las personas para salir de la pobreza y no sólo desde la

localidades "un metodología promocional masificable, recientemente descentralizada y participativa", que se apoye en los recursos sociales, técnicos y profesionales a nivel regional y local (Raczynski, 1995:251). Este programa, en ejecución desde 1991, ha tenido aspectos críticos como no determinar certeramente que capacidades deja instaladas tanto en la localidad como en el municipio. Por otro lado, "por sí mismo difícilmente contribuye a combatir la pobreza. Requiere apertura, sintonía y colaboración de todas las instituciones públicas que operan a nivel local" (Raczynski, 1995:254), lo cual no siempre es posible de encontrar o construir. 
carencia $^{12}$, es un fenómeno que se puede revertir, que no impide la creación o desarrollo de capital social, ya que en ellas "existe una capacidad latente que puede ser potenciada a través de estrategias que promuevan la confianza interna y externa, la cooperación y la reciprocidad” (Mideplan, 2002:39).

\section{Importancia de la Investigación Planteada}

En general, los estudios de pobreza, si bien han incorporado elementos de la cultura, como las significaciones, sentidos, emociones, expectativas y valores entre otros, más allá de aspectos “objetivos” o "absolutos” como el nivel de ingreso, nivel educacional, salud y trabajo no han incorporado el componente del interventor, como agente capaz de crear y recrear la realidad, en este caso, de la política social. Así, la manera de entender la pobreza centrada en aspectos culturales o de orden "objetivo”, llevan a propuestas distintas de intervención en el área. Sin embargo, la representación social de la noción de pobreza del interventor (que permite operar la política social en sus diversos niveles) no aparece, para los diseñadores de políticas sociales, como un componente interesante de atribuir al logro o no de los objetivos de la intervención.

Lo anterior, toma relevancia en la medida en que el programa Puente es una apuesta política, técnica y también humana de superación de la pobreza, en el sentido de que se promueve el encuentro cara a cara, entre el agente público y la familia. Por lo mismo, los agentes del programa ponen en juego las visiones e imágenes que poseen de la pobreza y el ser pobre. Este programa cambia la mirada de intervención, centrándola en la relación individual que establece el Apoyo Familiar y algún represen-

12 "Una definición acertada sobre la extrema pobreza no debe asumir como rasgo constitutivo de ella, la ausencia total de condiciones o recursos subjetivos en las personas que enfrentan dicha condición, ni tampoco la imposibilidad de generar o potenciar esas capacidades, a favor de procesos de desarrollo que pueden contribuir a superar la condición de deterioro material y psicoemocional que enfrentan las personas extremadamente pobres." (Mideplan, 2002:38). tante de la familia. La relación que se construye, entonces, es "uno a uno ${ }^{13}$ ", a diferencia de programas anteriores cuyo énfasis era la organización social y el soporte comunitario de los más pobres. En la relación establecida entre el agente estatal y algún miembro de la familia se juega el éxito de la intervención, aspecto por lo demás crítico y complejo, ya que se debe confiar en la capacidad y habilidad que posee este agente para vincularse con el sujeto "pobre".

El preguntarse por la cualidad del vínculo que se establece entre ambos sujetos no es menor, ya que éste ha sido un aspecto descuidado en los proyectos de modernización del Estado, a pesar de la existencia de una cultura funcionaria que construye la relación con el usuario desde la estigmatización y discriminación de los más pobres, puesto que ellos -los más pobres- a lo largo de la historia han expresado la dependencia e "inferioridad social"14 respecto del resto de la sociedad.

La investigación plantea como premisa que los cambios de las familias en términos de la superación de la pobreza, dependerán de lo que se construya y de la manera cómo construya esta interacción. El identificar y comprender estos significados, imágenes, ideas acerca de la pobreza, que subyacen al accionar del agente, permitirá dar cuenta de los nudos que tensionan su trabajo, así como la pertinencia y adecuación de su quehacer con el conjunto del diseño del programa y la realidad de cada familia.

\section{Objetivos de la Investigación}

Los objetivos generales de la investigación fueron analizar y comparar las representaciones sociales de la pobreza de los agentes estatales que intervienen en la formulación y ejecución del Programa Puente en dos comunas de la Región Metropolitana, en tanto, como objetivos específicos, el estudio se

13 N.E: Las comillas son del editor. 14 N.E: Las comillas son del editor. 
propuso identificar y analizar la representación social de la pobreza presente en los diseñadores nacionales del Programa Puente y en los ejecutores municipales o jefes de unidades de intervención familiar a cargo del Programa Puente, como de los Apoyos Familiares, de dos comunas de la Región Metropolitana, así también caracterizar la práctica de intervención con las familias pobres, desde el relato del Apoyo Familiar.

\section{Metodología}

El enfoque metodológico de la investigación fue cualitativo, exploratorio y de estudio de casos que centra sus esfuerzos en caracterizar, analizar y comprender los sentidos y significados expresados y compartidos a través del lenguaje o discurso sobre los hechos sociales. La investigación operacionaliza el concepto de representación social de la pobreza a través de tres dimensiones del discurso: 1.- Los conceptos que utiliza el entrevistado 2.- Las afirmaciones, hipótesis o premisas del entrevistado en relación al problema de la pobreza; 3.- Y las explicaciones o modelos explicativos o causales sobre el fenómeno social de la pobreza según cada uno de los agentes estatales, entiéndase encargados Programa Puente nivel nacional (Fosis), Jefes de Unidad de Intervención Familiar Comunal (Juif) y Apoyos Familiares.

En el caso de los profesionales de nivel nacional, la entrevista se centró en la definición del fenómeno de la pobreza y el diseño del programa. En el caso del nivel comunal, se solicitó a los profesionales la definición del fenómeno de la pobreza y relatar su experiencia en términos de la ejecución comunal del programa.

Por último, para el nivel de los apoyos familiares, se les solicitó dar cuenta de su concepción del fenómeno de la pobreza, como también, relatar su práctica en la implementación del programa con las familias. Es decir, en el caso de los apoyos familiares, se enfatizó la descripción de experiencias vividas personalmente y en los contextos en los cuales se inscribieron. Bertaux denomina este tipo de relatos "relatos de prácticas", que permiten poner al que relata en relación con la acción en una determinada situación. Una acción que se desplaza en el tiempo y que puede ser muy bien descrita por la forma narrativa del relato propio a una entrevista en profundidad. (Daniel Bertaux en Les récits de vie, Nathan,Paris,1997).

El relato de prácticas que entregaron los Apoyos Familiares se realizó a partir del análisis de un caso de familia que cada entrevistado eligió como "significativo" a la comprensión del problema de la extrema pobreza. Las herramientas escogidas para la recolección de información en este trabajo fueron cualitativas y se trató de entrevistas en profundidad, individuales y entrevistas grupales. En tanto la Unidad de Observación, fueron los Diseñadores del Programa Puente a nivel nacional; implementadores municipales a cargo del programa en las comunas de El Bosque y Pudahuel, apoyos familiares de las comunas de El Bosque y Pudahuel de la Región Metropolitana.

\section{Hallazgos, Relevancia de la investigación y contribución para el Trabajo Social}

Los hallazgos de la investigación dan cuenta de semejanzas en las representaciones sociales de la pobreza entre los agentes estatales, tanto en los que formulan como los que ejecutan el Programa Puente. Ellos coinciden en la identificación de las causas estructurales y culturales de la pobreza, en las características de carencia y proactividad de las familias y en la definición del principio central de la acción para la superación de la pobreza, como es el reconocimiento de las capacidades de los más pobres. En este sentido, se concluye que existen comprensiones y acuerdos básicos en relación a las representaciones de la pobreza que cada uno de los profesionales y funcionarios posee, lo cual facilita un actuar coordinado y coherente en términos institucionales.

Sin embargo, la relación cara a cara o cercanía 
que establece el apoyo familiar con la familia moldea su manera de "bajar" o implementar los lineamientos de política a la realidad específica de las familias. Cada Apoyo Familiar aprende a leer estas claves y especificidades de las familias para así poder "traducir” los principios generales del Programa a la realidad a intervenir. Es aquí, en este "hacer", más que en las representaciones y discursos en torno a la pobreza, donde los apoyos familiares deben poner más de su esfuerzo hermenéutico y creativo.

Es en este nivel de la práctica, donde las "capacidades” de los más pobres muestran su evidencia; por lo tanto es a este nivel donde se juega la posibilidad que los más pobres puedan participar con sus propios recursos. Otro hallazgo está en relación con los principios de la superación de la pobreza, en el nivel nacional (Fosis) y comunal no aparecen aspectos relacionados con el desarrollo comunitario y el capital social presente en las orientaciones de las políticas de los años noventa. A nivel de los apoyos familiares, sí es posible identificar algunos de estos principios como potenciar la autogestión, generación de opinión, el no asistencialismo y el trabajo como necesidad. Sin embargo, ni en el nivel nacional ni comunal se señala cómo el Estado podría potenciar o valerse del plus que tendrían los más pobres de este país. Se dice que la pobreza tiene potencialidades, identifican la proactividad, la resiliencia y sus capacidades; pero no se especifica cómo el Estado podría potenciar dichas capacidades. ¿Bastaría con generar y acercar oportunidades, educar y descentralizar acciones?

En función de lo anterior, los apoyos familiares se distancian o diferencian del nivel nacional y comunal en lo que respecta al ámbito de los principios que guían la acción para la superación de la pobreza. Ellos sí buscan de manera más explícita, visualizar y potenciar las habilidades y capacidades específicas que poseen las personas y familias. Este último aspecto es interesante porque muestra la capacidad que poseen los apoyos familiares para re-diseñar los programas y ajustarlos, especialmente a las características que presenta cada familia, algo que ya se anunciaba y vislumbraba desde el nivel comunal.

A la vez, muestra la capacidad de los apoyos familiares de articular la representación de la pobreza con su práctica. Es decir, se logran vincular el diagnóstico de la pobreza con los principios orientadores de su accionar en la ejecución de los programas públicos. Ellos, en cierta forma, recuperan o actualizan lo que fueron los propósitos de las políticas de los 90, al decir que las políticas deben fortalecer la autogestión, orientar, identificar el motor de cambio, dar trabajo. Es decir, hacerse cargo de dos dimensiones importantes: las causas estructurales y las capacidades de los más pobres para activarlas en su favor.

El hecho de que estas capacidades de los más pobres se destaquen con tanta fuerza a nivel de los apoyos familiares y no así entre los profesionales de nivel nacional, ciertamente constituye un aspecto que puede ser problemático para el diseño e implementación de políticas para la superación de la pobreza. En esta distancia, se arriesga finalmente que la acción de intervención social quede supeditada a la habilidad y destreza de cada apoyo familiar para hacerla realidad.

En este sentido, si bien es un plus que las habilidades de los más pobres aparezcan a nivel local, también constituye un factor de alerta el hecho que solo sea visible en este nivel. Ciertamente la política no se construye sólo desde “arriba”, desde el nivel nacional y la estrategia de política no se construye solamente desde "abajo", es decir, desde los que intervienen e implementan directamente el programa. Se debiera siempre prever una retroalimentación de los niveles locales a los nacionales (y no solamente desde arriba hacia abajo), aspecto que en este estudio no aparece del todo claro.

Retomando los hallazgos acerca de los principios para la superación de la pobreza, en la representación social del nivel nacional (Fosis) y comunal, no aparecen aspectos relacionados con el desarrollo comunitario y el capital social presente en las 
orientaciones de las políticas de los años noventa. En ese sentido, se afirman principios como el de generar/acercar oportunidades e informar, directrices propias de la década dos mil, pero se abandonan principios como, por ejemplo, el desarrollo de capital social, organización y más participación característico de la década de los noventa. A nivel de los apoyos familiares en cambio, sí es posible identificar algunos de estos principios de los años noventa. Por ejemplo, a través de potenciar la autogestión, generación de opinión, el no asistencialismo y el trabajo, pero también se visualizan aquellos vinculados a la actual década como es el orientar e informar.

En este último punto, vale la pena preguntarse por la necesidad de continuidad de los énfasis de las políticas sociales de los noventa (participación, ciudadanía...). ¿Qué es lo que se pierde y que es lo que se gana dejando fuera las preguntas y las acciones orientadas a fortalecer la ciudadanía, la participación y la organización de estas familias en sus territorios? Ciertamente, el énfasis de los apoyos familiares en las capacidades familiares y sus habilidades nace de una constatación que les da la experiencia de trabajo con estas familias, la necesidad de incorporar una mayor participación organizada de las familias más que ser un principio de los años noventa, pareciera continuar siendo una necesidad sentida y urgente a conservar.

Este último punto sintoniza y es interesante de leer a la luz del pensamiento de Hanna Arendt, la cual enfatiza el espacio público como la esfera donde se constituye lo propiamente humano. Ella distingue entre el espacio privado y el público. El primero, es una esfera prepolítica, dominada por la necesidad. Ahí no hay libertad ni se establecen relaciones de igualdad, pero también es la esfera necesaria que ofrece un lugar seguro, un refugio y es la condición para la libertad.

El segundo espacio ostenta una supremacía existencial, aquí los sujetos se muestran ante los ojos de los demás y revelan su identidad. En el espacio público se constituye la acción que sólo se da con y entre los sujetos por medio del discurso, la palabra. En esta trama las circunstancias se tornan impredecibles, porque la acción de los sujetos, en tanto muestran la individualidad de cada uno, hacen que irrumpa lo inédito, lo novedoso en la cadena de acontecimientos. Aquí, nacen asuntos inciertos propios de la vitalidad de las cosas humanas.

La perspectiva de Arendt, apuesta por la libertad dado que la acción y el discurso expresan lo que cada individuo tiene de único, de extraordinario, se constituyen en el medio para la libertad, entendida como la habilidad para encararse a los acontecimientos para apostar a favor de la propia vida. Arendt expresa esto de la siguiente manera "Una vida sin acción ni discurso está literalmente muerta para el mundo; ha dejado de ser una vida humana porque ya no la viven los hombres” ${ }^{15}$.

En esto se expresa que la unión de la acción y el discurso, de la praxis y la lexis permite hablar de una vida humana, de un tiempo vital. La comunidad, el nosotros, se convierte en condición de la acción. Aquí radica el interés y pertinencia de la tesis de Arendt, a saber, sin la esfera pública, la identidad individual y la realidad devienen inciertas. Los hombres no pueden actuar en soledad, necesitan la presencia de los otros.

Retomando esta tesis, se hace interesante mirar la política pública y los programas sociales por sus formas de acción, por sus mecanismos de intervención social, ya que a través de ellos, en la acción, se construye el ámbito público. Por esto, los procesos de intervención social no pueden ser vistos como simples formas de operacionalizar políticas, sino como creadores de un espacio público peculiar. En ese sentido, no se debe olvidar que es la propia política la que coloca el abanico de las posibilidades que poseen los sujetos de intervención (Matus, 2002).

El Programa Puente trasluce esta mirada, sobre todo si se considera que en el nivel de quienes

15 Ver La Condición Humana, Paidós, pág. 20.

$-131-$ 
trabajan directamente o los apoyos familiares, la intervención se cruza por lo simbólico. Es decir, en ese espacio se posibilitan los ritos vinculantes, "el acordar compromisos, el tomar en cuenta como sujetos a las propias familias. Es decir, ya no simplemente como objetos de política.”(Matus, 2002: 74). Así, la acción que gesta este Programa se lee desde lo que posibilitan los apoyos familiares con cada familia para que se constituyan desde y en la esfera pública, espacio en que cada sujeto coloca cosas nuevas en el mundo, se hace ciudadano. El dejar este elemento a la habilidad y capacidad de cada apoyo familiar hace incierto y opaco este espacio. Por lo anterior, el Programa debiera explicitar claramente que la intervención no debe sólo procurar cubrir necesidades vinculadas al espacio privado sino reforzar y potenciar el espacio público, propio de la "naturaleza humana".

Lo anterior es relevante para Trabajo Social en tanto el Programa Puente viene a ser una forma de intervención muy ligada a los orígenes de la

\section{BIBLIOGRAFÍA}

- $\quad$ AGUILAR, JOSÉ, 1999. Entrevista en profundidad. Editorial Lumen/Hvmanitas. Argentina.

- $\quad$ ALONSO, LUIS, 1995. "Sujeto y discurso: el lugar de la entrevista abierta en las técnicas de la sociología cualitativa”. En Delgado y Gutiérrez. Métodos y técnicas cualitativas de investigación en ciencias sociales. Editorial Síntesis. España.

- $\quad$ ANDER-EGG, EZEQUIEL, 1994. Historia del Trabajo Social. Editorial Lumen. Argentina.

- BERGER, PETER Y LUCKMANN, THOMAS, 1994. La construcción social de la realidad. Editorial Amorrortu. Argentina

- $\quad$ FERES, JUAN, 2001. La pobreza en Chile en el año 2000. Convenio Mideplan/Cepal "Evaluación de la Magnitud de la pobreza”. División de estadística y proyecciones económicas. Santiago de Chile.

- FFRENCH-DAVIS, RICARDO, 1999. Entre el neoliberalismo y el crecimiento con equidad. Tres décadas de política económica en Chile. Editorial Dolmen. Chile.

- GARCÍA, ALVARO, 1994. “Consensos en la superación de la pobreza”. En: La pobreza: desafíos de ayer y hoy. Fundación Libertad y Desarrollo y Fundación Miguel Kast. Chile.

- GONZALEZ, SERGIO, 2001. Representación social de la
Profesión. Por otro lado, los hallazgos dejan ver los nudos y desajustes existentes entre el nivel de diseño y los que implementan la política social, ambos espacios constituidos principalmente por trabajadores sociales. Constatar, además, distancias entre el nivel de discurso y la práctica de los Apoyos Familiares requiere mirarse en función de las diversas maneras existentes pero invisibles a los ojos de la profesión, para legitimar las desigualdades en nuestra sociedad.

No es menor reconocer igualmente que este programa hace virar la manera de trabajar la pobreza desde el aparato público/municipal, el que no ha considerado a sus beneficiarios como sujetos de la política. Es en este sentido que contribuye la presente investigación: afirmar la necesidad de girar la profesión hacia otros horizontes, especialmente, tanto para aquellos profesionales que se desempeñan en niveles nacionales como en la acción "directa”, otorgando relevancia a este eslabón que media entre los diseñadores de la política y los destinatarios. noción de ciudadanía: construcción y ampliación de la ciudadanía en grupos articulados al sistema educacional. Tesis para optar al grado de Doctor en Psicología, Universidad de Chile. Santiago de Chile.

- GISSI, JORGE, 1990. Psicoantropología de la pobreza. Oscar Lewis y la realidad chilena. SIO. Santiago de Chile.

- HERNÁNDEZ, R, FERNÁNDEZ,C y BAPTISTA, P, (1996). Metodología de la investigación. Editorial Mc Grau Hill. México.

- JODELET, DENISSE, 1993 . "La Representación Social: fenómenos, conceptos y teorías”. En: Moscovici, “Psicología Social”, Vol.II. Editorial Paidós. Barcelona. España pp 469494.

- LARROULET, CRISTIÁN, 1994. "El diagnóstico del 70, las nuevas realidades y desafíos actuales en la lucha por erradicar la extrema pobreza”. En: La pobreza: desafíos de ayer y hoy. Fundación Libertad y Desarrollo y Fundación Miguel Kast. Chile.

- LAVÍN, JOAQUíN, 1994. "En la huella de Miguel Kast”. En: La pobreza: desafíos de ayer y hoy. Fundación Libertad y Desarrollo y Fundación Miguel Kast. Chile.

- $\quad$ LEIVA, FERNANDO, 1995. Los límites de la actual estrategia de lucha contra la pobreza y el dilema de las ongs. PAS, Taller de Reflexión, serie documentos de análisis. Santiago de Chile. 
- LEWIS, OSCAR, 1961. Antropología de la pobreza. Cinco familias. Fondo de cultura económica. México.

- $\quad$ LEWIS, OSCAR, 1964. Los hijos de Sánchez. Autobiografía de una familia mexicana. Fondo de cultura económica. México.

- LOMNITZ, LARISSA ADLER DE, 1977. Cómo sobreviven los marginados. Editorial siglo XXI. México.

- MARQUEZ, FRANCISCA, 2002. Chile Solidario. Ponencia Seminario sobre Chile Solidario organizado por Acción, Instituto Libertad y Desarrollo; Participa. Santiago de Chile.

- MARTINEZ, JAVIER Y PALACIOS, MARGARITA, 1996. Informe sobre la decencia. La diferenciación estamental de la pobreza y los subsidios públicos. Colección estudios urbanos. Ediciones Sur. Santiago de Chile.

- MARTINIC, SERGIO, 1992. Análisis estructural: presentación de un método para el estudio de lógicas culturales. Ediciones Cide. Santiago de Chile.

- MATTE, PATRICiA, 1994. Políticas prioritarias en la erradicación de la pobreza. En: La pobreza: desafíos de ayer y hoy. Fundación Libertad y Desarrollo y Fundación Miguel Kast. Chile

- MATUS, TERESA, 2002. "La intervención social bajo el resplandor de lo público”. En Hoy es mi Tiempo, una ventana a la Esperanza. Fosis. Santiago de Chile.

- MIDEPLAN, 1991. Un proceso de integración al desarrollo. Informe social 1990-1991. División de planificación, estudios e inversiones. Santiago de Chile.

- MIDEPLAN, 1991. Evolución de las políticas sociales en Chile, 1920-1991. División de planificación, estudios e inversiones. Santiago de Chile.

- MIDEPLAN, 2000. Posibilidades y limitaciones de las políticas económicas redistributivas: perspectivas de largo plazo. Unidad de estudios prospectivos, Mideplan. Santiago de Chile.

- MIDEPLAN, 2002. Síntesis de los principales enfoques, métodos y estrategias para la superación de la pobreza. Documento de trabajo. Departamento de evaluación social. Convenio Mideplan/Cepal. Santiago de Chile.

- MIDEPLAN, 2002. Sistema Chile Solidario. Gobierno de Chile.

- MIDEPLAN, 2002. Estrategias de Intervención Integral a favor de Familias en Extrema Pobreza. Secretaria ejecutiva Chile Solidario. Santiago de Chile.

- MOSCOVICI, SERGEI, 1993. Psicología social II: Pensamiento y vida social. Editorial Piados. Argentina.

- POTTER, JONATHAN, 1998. La representación de la realidad. Discurso, retórica y construcción social. Editorial Piados. Argentina.

- RACZYNSKI, DAGMAR, 1995. Estrategias para combatir la pobreza en América Latina: programas, instituciones y recursos. Cieplan. Santiago de Chile.

- SANDOVAL, JUAN, 1999. Entrevista a Denisse Jodelet. "El debate entre la teoría de las representaciones sociales y el socioconstruccionismo”. En Revista de Psicología y Ciencias Humanas Praxis. Facultad de Ciencias Humanas. Universidad Diego Portales. Año 1, № 1. Santiago de Chile.

- VALENTINE, CHARLES, 1970. La cultura de la pobreza. Crítica y contrapropuestas. Editorial Amorrortu. Argentina.

- WORMALD, GUILLERMO y RUIZ-TAGLE, JAIME,1999. Exclusión social en el mercado del trabajo. El caso de Chile. Organización Internacional del Trabajo. Santiago de Chile.

- $\quad$ http://www.programapuente.cl/login.html 